\title{
Retrieval of atmospheric parameters and data-processing algorithms for AVIRIS-NG Indian campaign data
}

\author{
Manoj K. Mishra ${ }^{1, *}$, Anurag Gupta ${ }^{1}$, Jinya John ${ }^{1}$, Bipasha P. Shukla ${ }^{1}$, \\ Philip Dennison $^{2}$, S. S. Srivastava ${ }^{1}$, Nitesh K. Kaushik ${ }^{1}$, Arundhati Misra ${ }^{1}$ and \\ D. Dhar ${ }^{1}$
}

${ }^{1}$ Space Applications Centre, Indian Space Research Organisation, Ahmedabad 380 015, India

${ }^{2}$ Department of Geography, University of Utah, Salt Lake City, UT, USA

\begin{abstract}
Applications of high-spatial resolution imaging spectrometer data acquired from the Airborne Visible/ Infrared Imaging Spectrometer-Next Generation (AVIRIS-NG) under India campaign 2015-16, require a thorough compensation for atmospheric absorption and scattering. The data-processing algorithms used for retrieving critically important atmospheric parameters, namely 'water vapour and aerosol optical depth (AOD)' over land and water surfaces are presented. Over land surfaces, the dark dense vegetation method and radiative transfer modelling are used for deriving spectral AOD for boxes of $20 \times 20$ pixels. For AOD retrieval over water surfaces, dark-target approximation is used with near-infrared and shortwave infrared measurements. Estimation of precipitable water vapour is carried out using short-wave hyperspectral measurements for each pixel. A differential absorption technique (continuum interpolated band ratio) has been used for this purpose. The retrieved AOD and water vapour values were compared with in situ sun-photometer and radiosonde data respectively, indicating good matches. Further, these parameters were used to derive 'atmospherically corrected surface reflectance and remote sensing reflectance', for land and water surface respectively, assuming horizontal surfaces having Lambertian reflectance.
\end{abstract}

Keywords: Aerosol, atmospheric correction, hyperspectral imaging, surface reflectance, water vapour.

\section{Introduction}

THE Next-Generation Airborne Visible/InfraRed Imaging Spectrometer (AVIRIS-NG) provides measurements in the wavelength range from $0.38 \mu \mathrm{m}$ to $2.5 \mu \mathrm{m}$ with spectral sampling of approximately $5 \mathrm{~nm}$ and with high spatial sampling depending on the altitude of the airborne sensor $^{1-3}$. AVIRIS-NG and other hyperspectral imaging

*For correspondence. (e-mail: manoj8187@sac.isro.gov.in) sensors acquire data in many adjacent spectral channels, such that for each pixel a complete reflectance spectrum can be derived from the wavelength region covered. The solar radiation incident on the surface and scattered from the surface to the sensor gets modulated due to absorption and scattering by the atmosphere. Almost half of the 0.4 $2.5 \mu \mathrm{m}$ spectral region is affected by atmospheric gas absorption and the shorter wavelength region below $1.0 \mu \mathrm{m}$ is significantly affected by molecular and aerosol scattering. There is now growing interest in using hyperspectral remote sensing for research and applications in a variety of fields, including geology, agriculture, forestry, ecology, coastal and inland water studies, environment hazards assessment and urban studies. In order to study surface properties using AVIRIS-NG data, accurate removal of atmospheric effects is required. The correction of atmospheric effects and conversion of radiances measured by the sensor to reflectance of surface materials are necessary. Since the mid-1980s, atmospheric correction algorithms have evolved from the earlier empirical line method and flat-field method to more recent ones based on rigorous radiative transfer modelling such as ATmospheric REMoval (ATREM) algorithm ${ }^{4}$ and Fast Line-ofsight Atmospheric Analysis of Spectral Hypercubes $(\text { FLAASH })^{5}$. Due to high temporal and spatial dynamicity of aerosol and water vapour, the most difficult task in atmospheric correction of any hyperspectral or multispectral remote sensing data is to derive accurate aerosol optical depth (AOD) and water vapour content. Atmospheric correction models such as ATREM and FLAASH retrieve water vapour for each pixel of the scene before atmospheric correction; however, they assume a single value of AOD for the entire scene. In reality over the Indian region, the assumption of a single AOD value for atmospheric correction of the whole scene does not always hold due to the heterogeneous nature of anthropogenic aerosol sources and high aerosol loading. Unlike over water surfaces where AOD can be easily retrieved for each pixel by approximating the water surface as dark in near-infrared wavelengths due to absorption, aerosol 
retrieval methods over land are necessarily different and more complex due to high reflectivity of the land surface in the entire spectrum from 0.4 to $2.5 \mu \mathrm{m}$. Apart from the requirement of accurate aerosol and water vapour information for atmospheric correction, these parameters are also useful for many applications such as aerosol and water vapour radiative forcing, Earth's radiation budget, etc.

Atmospheric carbon dioxide $\left(\mathrm{CO}_{2}\right)$, is another significant greenhouse gas which is increasing at a rapid rate $e^{6,7}$ and $\mathrm{CO}_{2}$ monitoring is done with ground-based and satellite-borne spectroscopic sensors ${ }^{8-11}$. High spatial resolution airborne sensing has been applied for the validation of satellite measurements ${ }^{12}$ and detection of point sources of trace gas and man-made emissions ${ }^{13-15}$. Moreover, spatial and temporal variability of atmospheric $\mathrm{CO}_{2}$ modulates the sensor-level signal and therefore retrieval of $\mathrm{CO}_{2}$ is also important for accurate atmospheric correction, especially in shortwave-infrared (SWIR) region ranging from 1.93 to $2.12 \mu \mathrm{m}$. However, in the present atmospheric correction algorithm, the standard value of atmospheric $\mathrm{CO}_{2}$ gas concentration for tropical atmosphere is used. In this article, data processing algorithms for (a) retrieval of AOD, (b) retrieval of water vapour and (c) atmospheric correction to generate AVIRIS-NG Level-2 (L2) products are described. Finally, the effect of atmospheric correction on reflectance spectra is discussed.

\section{Study area and data used}

The AVIRIS-NG level-1 (L1) radiance data over India in the regions listed in Table 1 were acquired across a range of dates in late 2015 and early 2016. Muddur is a town in Mandya district, Karnataka, India having an average elevation of $662 \mathrm{~m}$ above mean surface level. The region was covered by eight flight paths of AVIRIS-NG over mixed agriculture land cover. The data have potential use for development of vegetation monitoring techniques. Ambaji is a town in Banaskantha district, Gujarat, India, at an altitude of $480 \mathrm{~m}$ amsl. It is known for its historical and mythological connections with sites of cultural heritage. The AVIRIS-NG flights over Ambaji mostly covered regions of geological interest. These data can be used to examine the unique properties of hyperspectral data and how spectral information can be used to identify mineralogy. The AVIRIS-NG flights over Bhukia mostly covered regions of mineralogical interest. Primary gold occurs with sulphides in Palaeoproterozoic Aravalli rocks in the Bhukia area. Chilika is the largest brackish water lagoon in the Asian continent and is a very good site for studying optically complex waters from space-borne platforms. Chilika is connected by sea through a mouth in the northern sector and by many tributaries in the northern, central and southern sectors. Howrah, Ahmedabad and Hyderabad are urban sites. Over these sites the data could be used for studies on air quality, urban development and water resources. The Sholyar site is mainly covered by forests.

The AVIRIS-NG L1 data consist of calibrated atsensor radiance in 425 spectral channels, sun-sensor geometry, elevation and geo-location data. The in situ data (sun-photometer data, land surface reflectance data from a field spectroradiometer (FieldSpec-4, Malvern Panalytical/ASD), water-leaving reflectance (the normalized water-leaving radiance) from a radiometer and solar irradiance data from a remote cosine receptor (Malvern Panalytical/ASD)) collected during, before and after the airborne campaign were used for validation and analysis.

\section{Atmospheric correction over land}

The upward reflectance (normalized solar radiance) viewed at $z$ altitude by an airborne sensor (such as AVIRIS-NG) for a Lambertian surface can be approximated as follows ${ }^{16-19}$

$$
\begin{aligned}
& \rho_{\lambda}^{*}\left(\theta_{\mathrm{o}}, \theta, \varphi, z\right)=T^{\mathrm{gas}}\left(\theta_{\mathrm{o}}, \theta, \varphi, z\right) \\
& \quad \times\left[\rho_{\lambda}^{\mathrm{atm}}\left(\theta_{\mathrm{o}}, \theta, \varphi, z\right)+\frac{T\left(\theta_{\mathrm{o}}\right) T(\theta, z) \rho_{\lambda}^{S}\left(\theta_{\mathrm{o}}, \theta, \varphi\right)}{1-S_{\lambda} \rho_{\lambda}^{S}\left(\theta_{\mathrm{o}}, \theta, \varphi\right)}\right] .
\end{aligned}
$$

Here $\rho_{\lambda}^{*}\left(\theta_{\mathrm{o}}, \theta, \varphi, z\right)=\pi L_{\lambda}^{*}\left(\theta_{\mathrm{o}}, \theta, \varphi, z\right) / E_{S, \lambda} \cos \left(\theta_{\mathrm{o}}\right)$, where $L_{\lambda}^{*}\left(\theta_{0}, \theta, \varphi, z\right)$ is at-sensor radiance, and $E_{S, \lambda}$ is the solar flux at the top of the atmosphere (TOA). The terms on the right-hand side (RHS) of eq. (1) are the surface reflectance $\left(\rho_{\lambda}^{s}\left(\theta_{0}, \theta, \varphi\right)\right)$ and the atmospheric quantities related to the radiative field in the coupled system. The at-sensor radiance, like all of the radiative quantities in eq. (1), depends on the radiation line-sight expressed by the angles $\theta_{0}, \theta, \varphi$ and $z$, i.e. the solar zenith (with respect to nadir), sensor zenith (with respect to nadir), relative azimuth and sensor altitude respectively. The radiative quantities in eq. (1) are the intrinsic reflectance of the molecule and aerosol layer, $\rho_{\lambda}^{\mathrm{atm}}\left(\theta_{0}, \theta, \varphi, z\right)$, known as

Table 1. Summary of AVIRIS-NG data used in the present study

\begin{tabular}{llll}
\hline Flight date & Site & Latitude/longitude & Site type \\
\hline $10 / 01 / 2016$ & Muddur & $11.79^{\circ} \mathrm{N} / 76.64^{\circ} \mathrm{E}$ & Agriculture \\
$02 / 02 / 2016$ & Ambaji & $24.35^{\circ} \mathrm{N} / 72.85^{\circ} \mathrm{E}$ & Geology \\
$03 / 02 / 2016$ & Bhukia & $23.64^{\circ} \mathrm{N} / 74.26^{\circ} \mathrm{E}$ & Geology \\
$27 / 12 / 2015$ & Chilika & $19.61^{\circ} \mathrm{N} / 85.38^{\circ} \mathrm{E}$ & Lagoon \\
$27 / 02 / 2016$ & Howrah & $2263^{\circ} \mathrm{N} / 88.31^{\circ} \mathrm{E}$ & Urban \\
$03 / 03 / 2016$ & Howrah & $22.64^{\circ} \mathrm{N} / 88.37^{\circ} \mathrm{E}$ & Urban \\
$03 / 03 / 2016$ & Howrah & $22.62^{\circ} \mathrm{N} / 88.38^{\circ} \mathrm{E}$ & Urban \\
$14 / 02 / 2016$ & Ahmedabad & $23.02^{\circ} \mathrm{N} / 72.43^{\circ} \mathrm{E}$ & Urban \\
$11 / 02 / 2016$ & Ahmedabad & $22.97^{\circ} \mathrm{N} / 72.40^{\circ} \mathrm{E}$ & Urban \\
$19 / 12 / 2015$ & Hyderabad & $17.53^{\circ} \mathrm{N} / 78.33^{\circ} \mathrm{E}$ & Urban \\
$19 / 12 / 2015$ & Hyderabad & $17.49^{\circ} \mathrm{N} / 78.2^{\circ} \mathrm{E}$ & Urban \\
$07 / 01 / 2016$ & Sholayar & $10.53^{\circ} \mathrm{N} / 76.66^{\circ} \mathrm{E}$ & Forestry \\
\hline
\end{tabular}




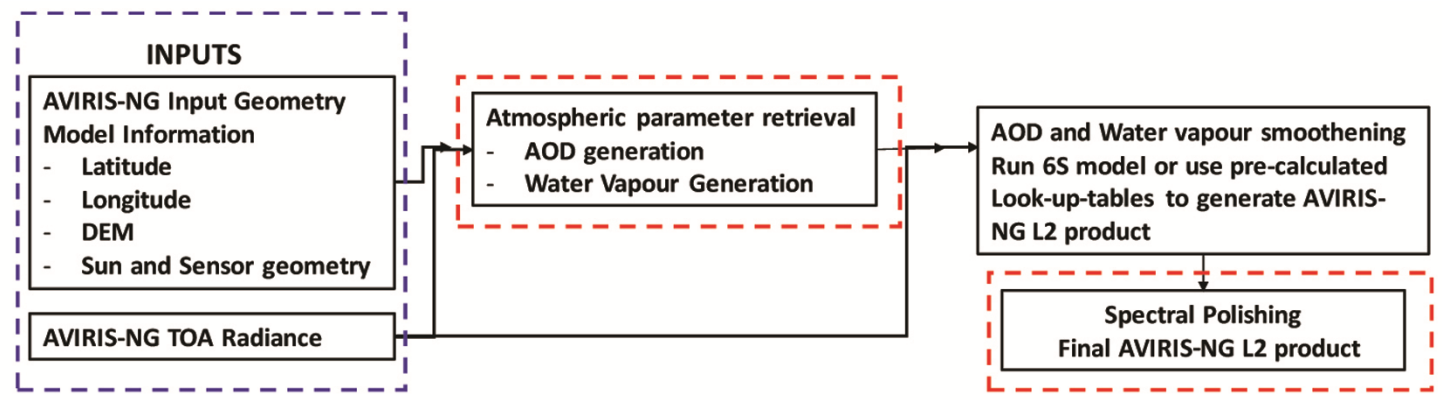

Figure 1. Block diagram for atmospheric correction of AVIRIS-NG data to generate L2 product.

path reflectance; the spherical albedo, $S_{\lambda}$ and the components of flux transmission. $T^{\text {gas }}\left(\theta_{0}, \theta, \varphi, z\right)$ is the gaseous transmittance, whereas $T\left(\theta_{\mathrm{o}}\right)=\exp \left(-\tau / \cos \left(\theta_{\mathrm{o}}\right)+t_{\mathrm{d}}\left(\theta_{\mathrm{o}}\right)\right)$ and $T(\theta)=\exp \left(-\tau / \cos (\theta)+t_{\mathrm{d}}(\theta)\right)$ are the summed direct and diffuse components respectively, of the total transmittance for the illumination (descending) and view (ascending) directions. $\tau$ is the total optical thickness and $\tau_{z}$ is the optical thickness of the layer under the aircraft. Figure 1 shows the steps involved in atmospheric correction.

The objective of atmospheric correction is to derive surface reflectance $\rho_{\lambda}^{s}\left(\theta_{0}, \theta, \varphi\right)$ from at-sensor radiance $L_{\lambda}^{*}\left(\theta_{0}, \theta, \varphi, z\right)$. For this, all quantities on the RHS of eq. (1), except $\rho_{\lambda}^{s}\left(\theta_{0}, \theta, \varphi\right)$ must be known. Among these, estimation of $\rho_{\lambda}^{\mathrm{atm}}\left(\theta_{0}, \theta, \varphi, z\right)$ and $T^{\mathrm{gas}}\left(\theta_{0}, \theta, \varphi, z\right)$ is the most difficult. The former quantity depends on AOD, while the latter depends on atmospheric gases (specially water vapour). Once the values of AOD and water vapour are known, these can be used as input to run a radiative transfer code ${ }^{19}$ or MODTRAN to estimate all the other quantities, except $\rho_{\lambda}^{s}\left(\theta_{0}, \theta, \varphi\right)$ in eq. (1), to complete the task of atmospheric correction. Therefore, the main problem in atmospheric correction is to derive accurate values of AOD and water vapour.

\section{Aerosol retrieval and validation over land}

Quantitative analysis of AOD can be performed by applying radiative transfer theory in the atmosphere-earth coupled system, for the atmospheric correction of hyperspectral remote sensing data. Here we have described a physically based algorithm to retrieve AOD at $0.55 \mu \mathrm{m}$ from airborne acquired data in the visible and SWIR range. The physical basis of the algorithm is taken from Kaufman and co-workers ${ }^{20-22}$, which is currently used for AOD retrieval from MODIS data over land and is modified in accordance with airborne AVIRIS-NG data. The other aerosol retrieval algorithms such as enhanced deepblue algorithm ${ }^{23}$ and clear-composite algorithm ${ }^{24}$ could not be used here due the requirement of static surface reflectance database and time-series observations from a geostationary platform respectively.
AOD retrieval algorithm relies on the correlation between surface reflectance in the visible and SWIR $(2.1 \mu \mathrm{m})$ spectral domains ${ }^{22}$. For retrieval of AOD at the visible wavelength around $0.55 \mu \mathrm{m}$ from AVIRIS-NG data, the assumptions made are: (a) aerosols are transparent in the $2.1 \mu \mathrm{m}$ channel; (b) the surface reflectance in the visible channels 0.47 and $0.66 \mu \mathrm{m}$ is a function of the surface reflectance at $2.1 \mu \mathrm{m}$, the scattering angle and the normalized vegetation difference index (NDVI) based on 1.24 and $2.1 \mu \mathrm{m}$ given by $\mathrm{NDVI}_{\mathrm{SWIR}}=\left(\rho_{1.24}-\rho_{2.1}\right) /\left(\rho_{1.24}+\rho_{2.1}\right)$.

\section{Visible/SWIR surface reflectance relationship}

Similar to the MODIS AOD algorithm, we used the relationship between the visible and SWIR channel surface reflectance given by

$$
\begin{aligned}
& \rho_{0.66}^{s}=f\left(\rho_{2.1}^{s}\right)=\rho_{2.1}^{s} S_{0.66 / 2.1}+C_{0.66 / 2.1}, \\
& \rho_{0.47}^{s}=g\left(\rho_{0.66}^{s}\right)=\rho_{0.66}^{s} S_{0.47 / 0.66}+C_{0.47 / 0.66},
\end{aligned}
$$

where $S$ and $C$ are slope and intercept respectively, given by

$$
\begin{aligned}
S_{0.66 / 2.1}= & \rho_{0.66 / 2.1}^{\mathrm{NDVI}_{\text {SWIR }}}+0.002 \Phi-0.27, \\
C_{0.66 / 2.12}= & -0.00025 \Phi+0.033, \\
S_{0.47 / 0.66}= & 0.49 ; C_{0.47 / 0.66}=0.005, \\
\rho_{0.66 / 2.1}^{\mathrm{NDVI}_{\text {SWIR }}}= & 0.4 \text { for } \mathrm{NDVI}_{\mathrm{SWIR}}<0.25, \\
\rho_{0.66 / 2.1}^{\mathrm{NDVI}_{\mathrm{SWIR}}}= & 0.6 \text { for } \mathrm{NDVI}_{\mathrm{SWIR}}>0.75, \\
\rho_{0.66 / 2.1}^{\mathrm{NDVI}_{\mathrm{SWIR}}}= & 0.4+0.4\left(\mathrm{NDVI}_{\mathrm{SWIR}}-0.25\right) \\
& \text { for } 0.25 \leq \mathrm{NDVI}_{\mathrm{SWIR}} \leq 0.75,
\end{aligned}
$$

and scattering angle $\Phi$ is given by $\Phi=\cos ^{-1} \times$ $\left[\cos \left(\theta_{\mathrm{o}}\right) \cos (\theta)+\sin \left(\theta_{\mathrm{o}}\right) \sin (\theta) \cos (\varphi)\right]$. 

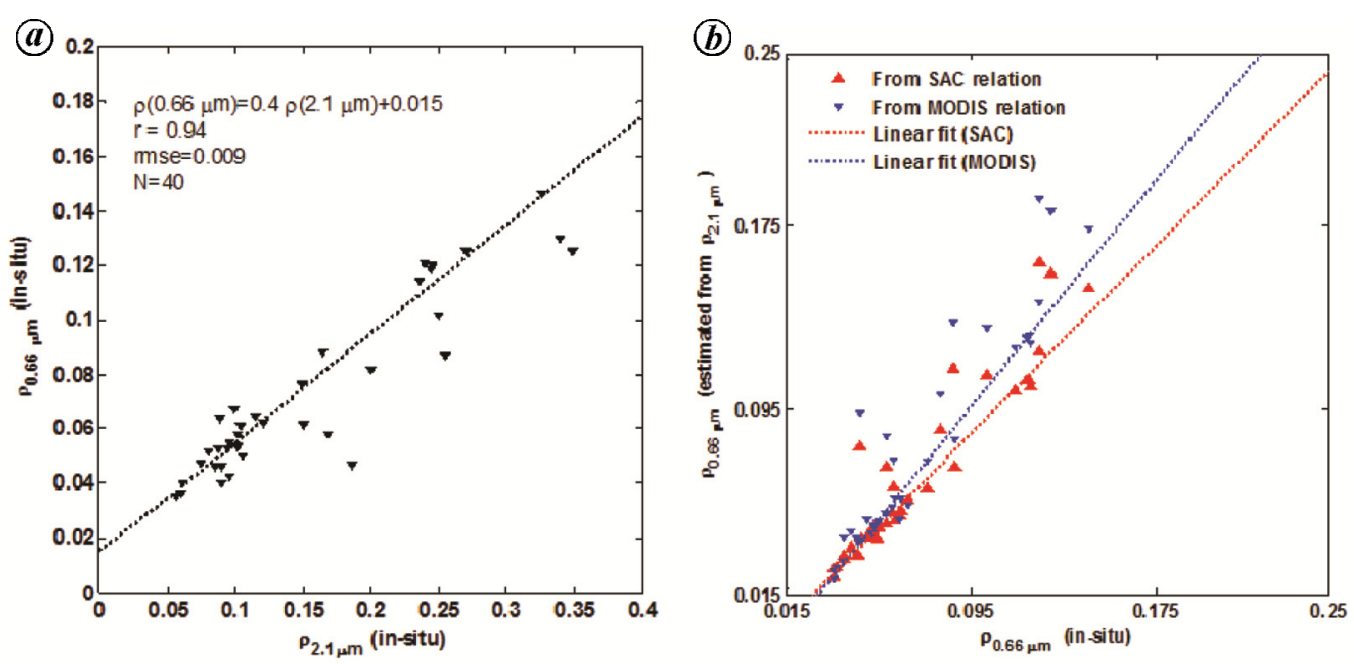

Figure 2. $\boldsymbol{a}$, Scatter plot between in-situ surface reflectance at $0.66 \mu \mathrm{m}$ and at $2.1 \mu \mathrm{m}$. Forty data points corresponding to densely vegetated and less vegetated land covers have been carefully selected based on NDVI SwIR $_{\text {val- }}$ ues. $\boldsymbol{b}$, Scatter plot and linear fitted line between estimated and in-situ surface reflectance in $0.66 \mu \mathrm{m}$ channel using optimized visible/SWIR surface reflectance relationship in eq. (2) (red points and red line) and MODIS visible/SWIR surface reflectance relationship (blue points and blue line).
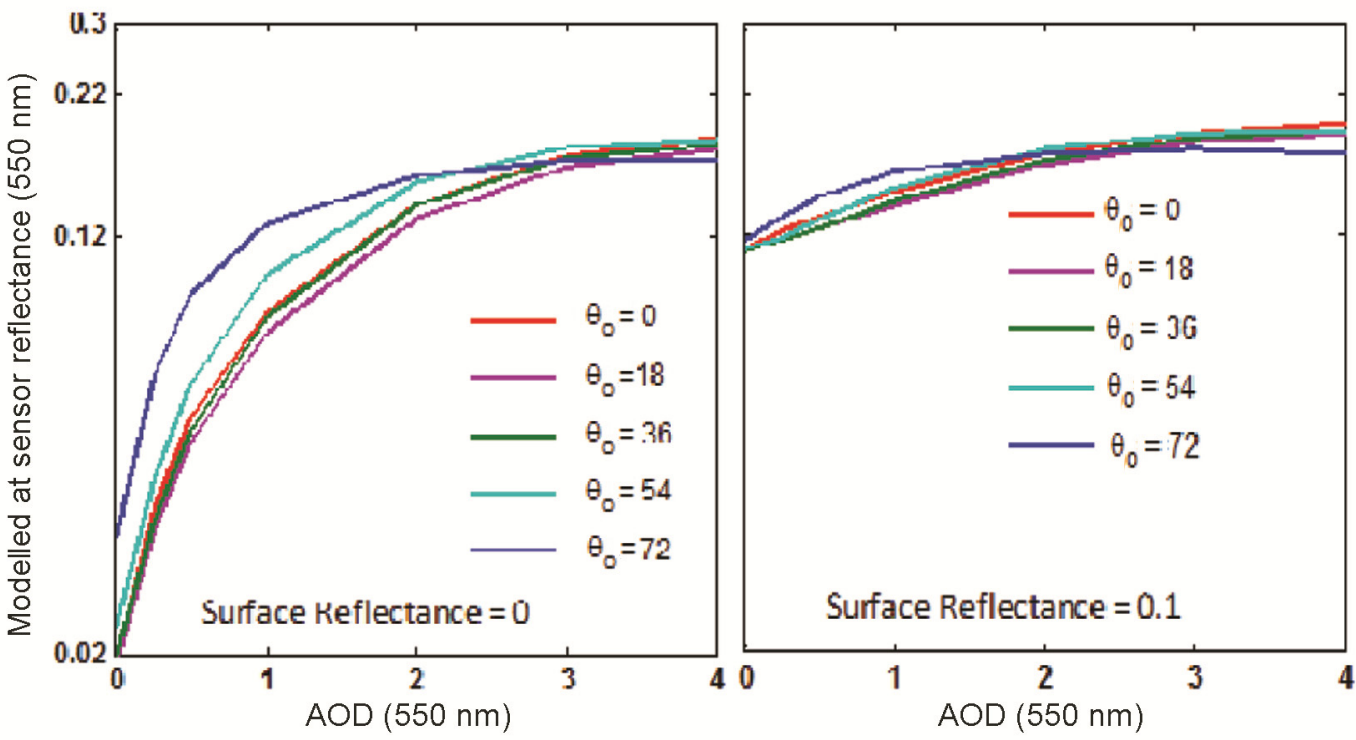

Figure 3. Simulated at-sensor reflectance at $0.55 \mu \mathrm{m}$ for different values of solar zenith angle $\left(\theta_{0}\right)$ and surface reflectance assuming the sensor at nadir. For radiative transfer simulations, sensor altitude of $4 \mathrm{~km}$ and continental aerosol model are assumed.

It is to be noted that the visible/SWIR surface reflectance relationship described in eqs (2) and (3) are slightly different from those used in the MODIS AOD algorithm $^{20-22}$. Actually, the visible/SWIR surface reflectance relationship is optimized for the Indian region using the in situ surface reflectance data measured during the AVIRIS-NG flights. These in situ data are carefully selected based on known land-cover type and $\mathrm{NDVI}_{\mathrm{SWIR}}$ values. Figure $2 a$ shows the high correlation between insitu surface reflectance in 0.66 and $2.1 \mu \mathrm{m}$. Figure $2 b$ shows the scatter plot for estimated surface reflectance at
$0.66 \mu \mathrm{m}$ using surface reflectance in $2.1 \mu \mathrm{m}$ channel. It is clear that the estimated reflectance is less scattered with respect to actual values of surface reflectance when optimized visible/SWIR surface reflectance relationship is used. Also, the slope of the linear fitted line in this case (red dotted line) is more closer to 1 : 1-line compared to that when the MODIS algorithm is used. The slope, intercept, correlation coefficient $\left(r^{2}\right)$ and RMSE for the present case are $1.016,-0.011,0.9733$ and 0.0064 respectively. On the other hand, when MODIS visible/SWIR surface reflectance relationship is used, the slope, intercept, 
(a)

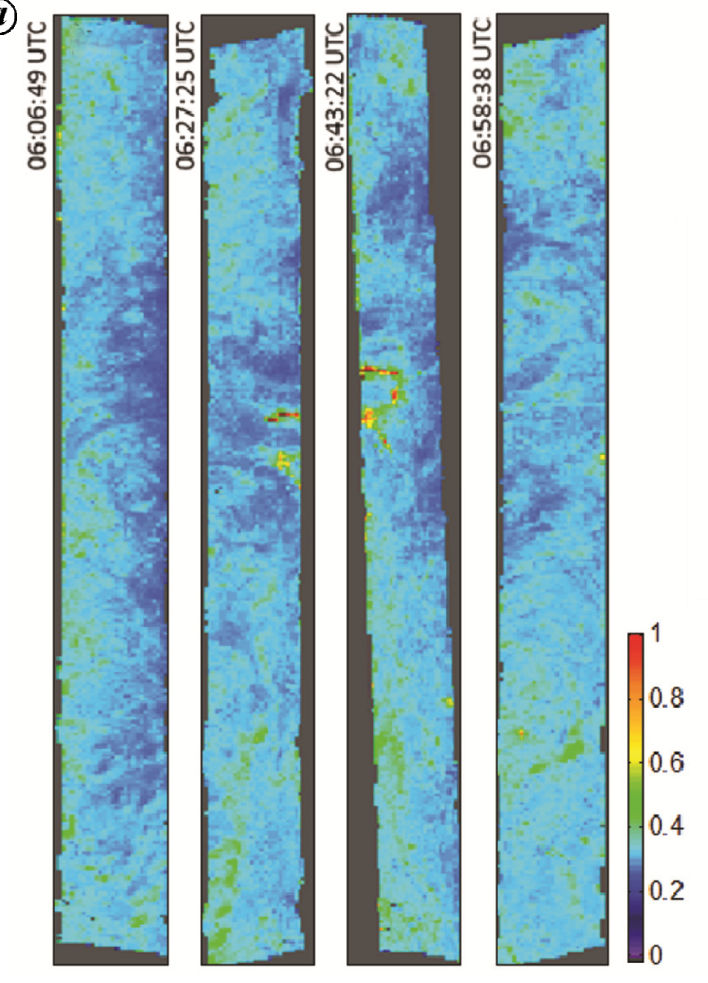

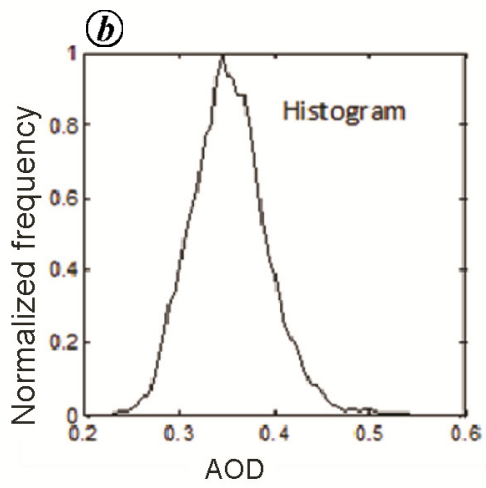

Figure 4. $\boldsymbol{a}$, Aerosol optical depth (AOD) maps for AVIRIS-NG data acquired on 2 February 2016 over the Ambaji region. $\boldsymbol{b}$, Histogram of AOD for all four flight lines. Mean AOD is around 0.35 and most of the AOD values lie in the range $0.3-0.4$.

correlation coefficient $\left(r^{2}\right)$ and RMSE are 1.22 , $-0.0193,0.97$ and 0.0074 respectively. Thus the visible/ SWIR surface reflectance relationship described in eqs (2) and (3) shows lower RMSE, intercept closer to zero, slope close to unity and high correlation relative to MODIS visible/SWIR surface reflectance relationship. Hence, we used eqs (2) and (3) for the estimation of surface reflectance in $0.66 \mu \mathrm{m}$ channel.

\section{Aerosol look-up table}

The look-up table (LUT) contains pre-computed optical properties (path reflectance, spherical albedo and upward/ downward transmittance) of aerosol at four discrete wavelengths $(0.47,0.55,0.66$ and $2.1 \mu \mathrm{m})$ for several values of aerosol total loadings, and for a variety of geometries (solar zenith, sensor zenith and relative azimuth angles). For discrete AODs ( $\tau_{0.55}=0.0,0.5,1.0,2.0$, etc.), assuming a continental aerosol model pre-computed LUTs were generated. Scattering/extinction properties of aerosol size distributions were determined by the radiative transfer code of Vermote et al. ${ }^{19}$. Assuming the Rayleigh atmosphere and realistic layering of aerosols, a radiative transfer calculation was used to simulate at-sensor reflectance. In addition, atmospheric properties vary by sun/sensor geometry; so at discrete values of solar and observation angles, there are determined prop- erties of TOA reflectance, atmospheric transmission and spherical albedo for a particular indexed AOD. Figure 3 shows simulated TOA reflectance for a dark surface and a surface with surface reflectance of 0.1 , as a function of AOD for different solar zenith angles and a nadir-viewing sensor. It is to be noted that for high AOD loading and surface reflectance values, the TOA signal becomes less sensitive to AOD; therefore, AOD retrieval for high aerosol loading and over bright targets is not possible. For this reason, AOD is retrieved at binned spatial resolution of $20 \times 20$ pixels to have sufficient number of dark vegetated pixels in the box.

\section{AOD retrieval}

Using eqs (2) and (3), and Rayleigh-corrected SWIR channel measurement, the surface reflectance in $0.66 \mu \mathrm{m}$ was estimated for averaged non-cloudy vegetated pixel in $20 \times 20$ pixel box, which was then used to estimate the sensor-level reflectance for different aerosol loadings with the help of pre-computed LUTs. The AOD value for which there was minimum error between the estimated and measured sensor-level reflectance was considered as the solution.

Figure $4 a$ and $b$ shows the AOD maps and normalized histogram of derived AOD over Ambaji. The mean AOD was found to be 0.35. In Ambaji region, AOD varies from 
0.25 to 0.45 ; therefore, use of mean AOD value in whole scene for correction can introduce significant error in derived surface reflectance. Figure $5 a-c$ shows a true colour image, AOD mosaic and normalized histogram of derived AOD over Bhukia respectively. In the Bhukia region mean $A O D$ was around 0.19 and most of the AOD values were in the range $0.1-0.2$, except for the ovalshaped region represented by red dots. Thus most of region showed clear atmospheric conditions with an exceptionally high AOD plume in lower part. It was found that the oval-shaped region encompasses a cement factory (MAHI Cement Factory, Figure $5 d$ ) which is responsible for the large suspension of fine aerosol particles in the atmosphere. Table 2 shows the in situ and derived AOD values at 13 locations in Muddur, Karnataka, while Figure 6 shows the scatter plot. The linear correlation coefficient and root mean square error were 0.71 and 0.024 respectively.
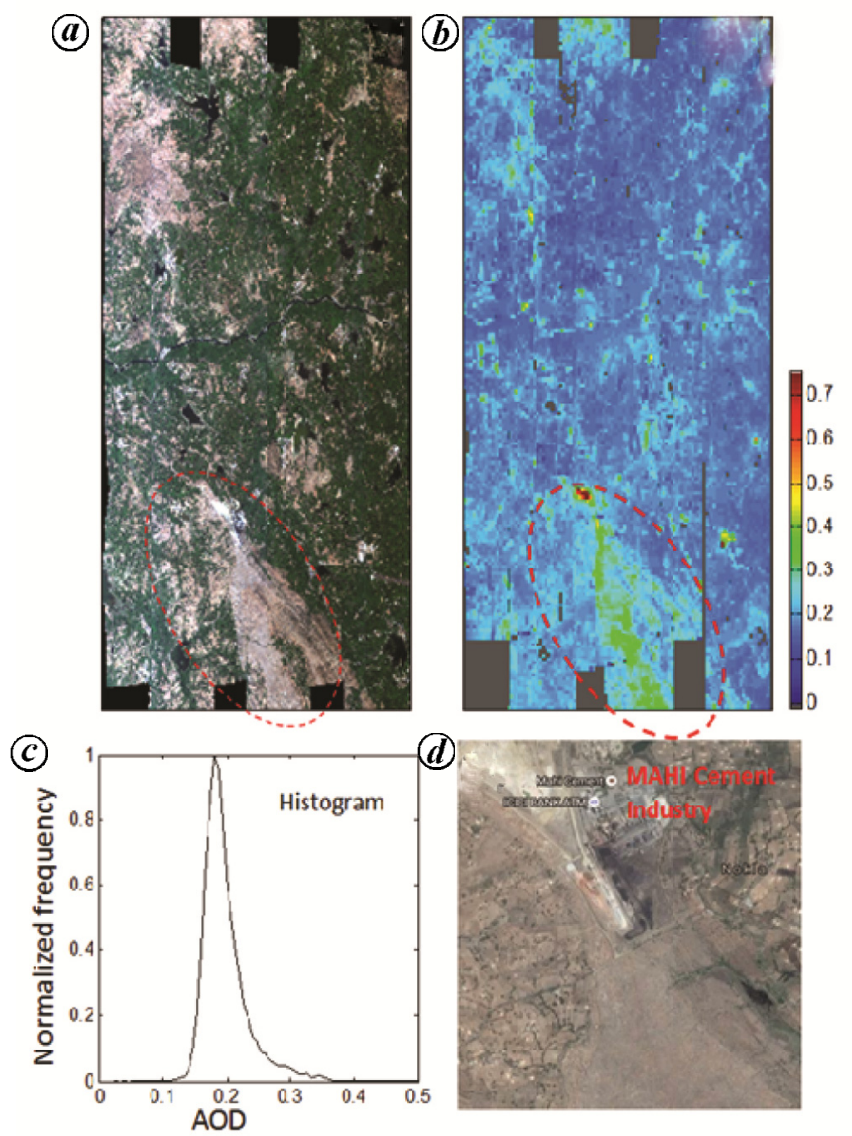

Figure 5. (a) True colour mosaic, (b) AOD mosaic and (c) AOD histogram for data acquired on 2 February 2016 over Bhukia region. Mean AOD is around 0.19 and most of the AOD values (except for the ovalshaped region represented by red dots) lie in the range $0.1-0.2$. The region covered mostly shows clear atmospheric condition with an exceptionally high AOD plume in lower part. The oval-shaped region represented by red dots was found to encompass a cement factory, which was responsible for the continuous suspension of fine aerosol particles in the atmosphere in this region. (d) Google Earth image showing haziness in the region around the cement factory.

\section{Retrieval and validation of precipitable water vapour over land}

The continuum interpolated band ratio (CIBR) differential absorption technique was used to estimate water vapour from AVIRIS-NG radiances ${ }^{25}$. This method characterizes an absorption feature in the presence of an absorption continuum. Fowle ${ }^{26}$ demonstrated the use of near-infrared absorption bands for the estimation of water vapour. Later, Frouin et al. ${ }^{27}$ proposed a differential absorption technique where two channels centred on the maximum water vapour absorption band near $940 \mathrm{~nm}$ were used for column water vapour retrieval. The ratio of the radiance in the two channels gives an estimate of the water vapour present in the atmosphere. They used a spectral band in the water vapour absorption region and two other channels in the nearby non-water vapour absorption regions. Basically, the channels used were $940 \mathrm{~nm}$ water absorption band, $867 \mathrm{~nm}$ and $1009 \mathrm{~nm}$ nonwater absorption bands. The present study also uses this approach.

Initially, we chose one measurement channel and two reference channels. The radiances from these channels were extracted for a selected AVIRIS scene. This was done for a certain pixel in the scene. After extraction of radiances, the ratio was calculated as follows

$$
R_{\mathrm{CIBR}}=\frac{L_{\mathrm{m}}}{w_{\mathrm{r} 1} L_{\mathrm{r} 1}+w_{\mathrm{r} 2} L_{\mathrm{r} 2}},
$$

where $L_{\mathrm{m}}, L_{\mathrm{r} 1}$ and $L_{\mathrm{r} 2}$ are radiances in the measurement and reference channels respectively.

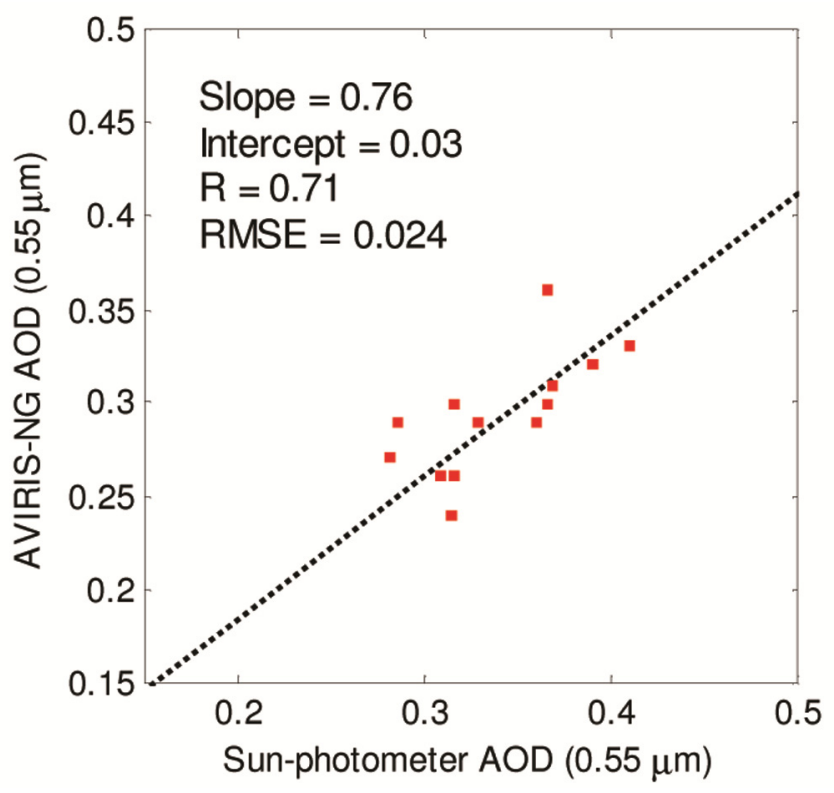

Figure 6. Scatter plot of in situ (sun-photometer) and AVIRIS-NGderived AOD values. 


$$
\begin{aligned}
& w_{\mathrm{r} 1}=\frac{\lambda_{\mathrm{r} 2}-\lambda_{\mathrm{m}}}{\lambda_{\mathrm{r} 2}-\lambda_{r 1}}, \\
& w_{\mathrm{r} 2}=\frac{\lambda_{\mathrm{m}}-\lambda_{\mathrm{r} 1}}{\lambda_{\mathrm{r} 2}-\lambda_{r 1}},
\end{aligned}
$$

where $\lambda_{\mathrm{m}}, \lambda_{\mathrm{r} 1}$ and $\lambda_{\mathrm{r} 2}$ correspond to the measurement and reference channels respectively. This ratio is related to the water vapour content $(W)$ by the following relation

$$
R_{\mathrm{CIBR}}=\left(-\alpha W^{\beta}\right),
$$

where $\alpha$ and $\beta$ are coefficients. Finally, the total path water vapour content $\left(V_{\mathrm{p}}\right)$ was derived for which the total column water vapour content was first calculated as follows

$$
\begin{aligned}
& W=V_{p}\left(\frac{1}{\cos \theta_{\mathrm{o}}}+\frac{1}{\cos \theta}\right)^{-1}, \\
& V_{\mathrm{p}}= \begin{cases}\left(\frac{-\ln R_{\mathrm{CIBR}}}{0.592}\right)^{1 / 0.568} & \text { non-vegetation } \\
\left(\frac{-\ln R_{\mathrm{CIBR}}}{0.599}\right)^{1 / 0.575} & \text { vegetation). }\end{cases}
\end{aligned}
$$

The relation between $V_{\mathrm{p}}$ and $R_{\mathrm{CIBR}}$, i.e. the coefficients $\alpha$ and $\beta$ were obtained using MODTRAN simulations for different atmospheric and surface conditions ${ }^{28}$. We demonstrate the retrieval of water vapour content for a scene over Howrah on 19 December 2015 using CIBR technique (Figure 7). Further, to validate the retrieval, we have used the Wyoming sounding data. Wyoming weather web provides in situ precipitable water vapour for several

Table 2. The in-situ (sun-photometer) and retrieved AOD values in the region covered by AVIRIS data over Muddur, Karnataka on 10 January 2016

\begin{tabular}{lccc}
\hline Latitude & Longitude & $\begin{array}{c}\text { AVIRIS-NG AOD } \\
(550 \mathrm{~nm})\end{array}$ & $\begin{array}{c}\text { Sun-photometer } \\
\text { AOD }(550 \mathrm{~nm})\end{array}$ \\
\hline 11.762 & 76.578 & 0.27 & 0.282 \\
11.761 & 76.585 & 0.24 & 0.314 \\
11.761 & 76.587 & 0.26 & 0.316 \\
11.756 & 76.605 & 0.31 & 0.369 \\
11.778 & 76.627 & 0.29 & 0.360 \\
11.796 & 76.630 & 0.30 & 0.365 \\
11.793 & 76.643 & 0.36 & 0.366 \\
11.858 & 76.666 & 0.30 & 0.316 \\
11.884 & 76.660 & 0.29 & 0.329 \\
11.944 & 76.652 & 0.29 & 0.286 \\
11.966 & 76.666 & 0.26 & 0.308 \\
11.774 & 76.568 & 0.32 & 0.390 \\
11.761 & 76.586 & 0.33 & 0.410 \\
\hline
\end{tabular}

Indian stations. The point for comparison was selected in close proximity to the Wyoming station coordinates so that there was less uncertainty in the retrieval. Due to this we found only a few match-up locations. Stations such as Ahmedabad, Kolkata, Hyderabad and Cochin have been considered here. Table 3 provides details regarding the
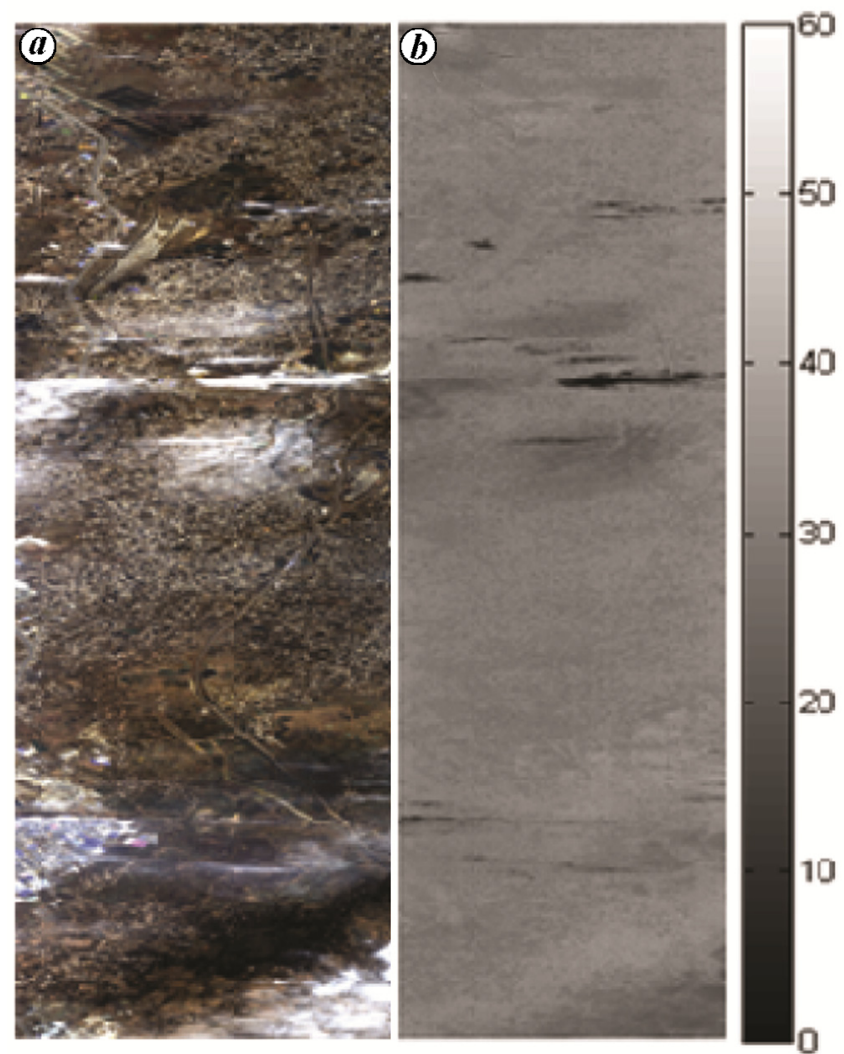

Figure 7. (a) RGB image of a scene over Howrah and (b) water vapour retrieved using CIBR technique.

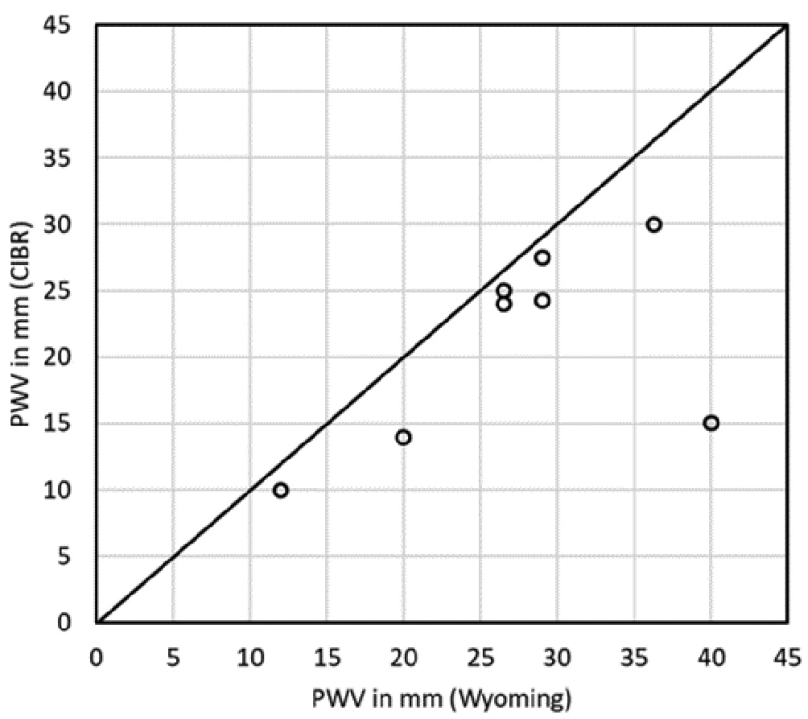

Figure 8. Scatter of water vapour obtained through in-situ and CIBR technique. 
Table 3. List of AVIRIS-NG sites with cloudy scenes along with coordinates. The coordinates of Wyoming location are also listed

\begin{tabular}{llll}
\hline Date & \multicolumn{1}{c}{ Site } & $\begin{array}{c}\text { Wyoming latitude/ } \\
\text { longitude/elevation }(\mathrm{m})\end{array}$ & $\begin{array}{c}\text { AVIRIS-NG } \\
\text { latitude } / \text { longitude }\end{array}$ \\
\hline $27 / 02 / 2016$ & Howrah & $22.65^{\circ} \mathrm{N} / 88.45^{\circ} \mathrm{E} / 6.0$ & $22.63^{\circ} \mathrm{N} / 88.31^{\circ} \mathrm{E}$ \\
$14 / 02 / 2016$ & Ahmedabad & $23.06^{\circ} \mathrm{N} / 72.63^{\circ} \mathrm{E} / 55.0$ & $23.02^{\circ} \mathrm{N} / 72.43^{\circ} \mathrm{E}$ \\
$03 / 03 / 2016$ & Howrah & $22.65^{\circ} \mathrm{N} / 88.45^{\circ} \mathrm{E} / 6.0$ & $22.64^{\circ} \mathrm{N} / 88.37^{\circ} \mathrm{E}$ \\
$03 / 03 / 2016$ & Howrah & $22.65^{\circ} \mathrm{N} / 88.45^{\circ} \mathrm{E} / 6.0$ & $22.62^{\circ} \mathrm{N} / 88.38^{\circ} \mathrm{E}$ \\
$11 / 02 / 2016$ & Ahmedabad & $23.65^{\circ} \mathrm{N} / 72.45^{\circ} \mathrm{E} / 55.0$ & $22.97^{\circ} \mathrm{N} / 72.40^{\circ} \mathrm{E}$ \\
$19 / 12 / 2015$ & Hyderabad & $17.45^{\circ} \mathrm{N} / 78.46^{\circ} \mathrm{E} / 545.0$ & $17.53^{\circ} \mathrm{N} / 78.33^{\circ} \mathrm{E}$ \\
$19 / 12 / 2015$ & Hyderabad & $17.45^{\circ} \mathrm{N} / 78.46^{\circ} \mathrm{E} / 545.0$ & $17.49^{\circ} \mathrm{N} / 78.2^{\circ} \mathrm{E}$ \\
$07 / 01 / 2016$ & Sholayar & $9.95^{\circ} \mathrm{N} / 76.26^{\circ} \mathrm{E} / 3.0$ & $10.53^{\circ} \mathrm{N} / 76.66^{\circ} \mathrm{E}$ \\
\hline
\end{tabular}

selected AVIRIS-NG scenes and Wyoming stations. Figure 8 is a scatter plot showing that the retrieved values are correlated with the sounding values. Only a few points could be compared on point-to-point basis due to the mismatch of AVIRIS-NG and Wyoming locations. Some points were very poorly correlated with in situ data due to the distance between the chosen AVIRIS pixels and Wyoming coordinates. This was the case of a scene over Sholayar, where poor correlation could be seen between the retrieved and in-situ values due to greater distance of around $78 \mathrm{~km}$ between AVIRIS-NG scene and Wyoming location. For other points a good correlation could be seen. It can be clearly seen from Figure 8 that CIBR slightly underestimates the retrieved water vapour content for low reflectance surfaces.

\section{Atmospherically corrected surface reflectance over land}

The retrieved AOD at resolution of $20 \times 20$ pixels can be given to any radiative transfer code to estimate the aerosol-dependent radiative quantities, path reflectance $\rho_{\lambda}^{\text {atm }}\left(\tau, \theta_{0}, \theta, \phi, z\right)$, spherical albedo $S_{\lambda}(\tau)$, downward transmittance $T\left(\theta_{0}\right)$ and upward transmittance $T(\theta)$. The retrieved water vapour and standard values of uniformly mixed gases such as $\mathrm{CO}_{2}, \mathrm{O}_{2}, \mathrm{CH}_{4}$ could be used for simulating gaseous transmittance $T^{\mathrm{gas}}\left(\theta_{0}, \theta, \phi, z\right)$. In the present study, we have used $6 \mathrm{~S}$ code to simulate these radiative quantities ${ }^{19}$. Having all these unknowns on the RHS of eq. (1) and putting sensor measured reflectance on the left-hand side of the equation, the solution for surface reflectance can be obtained. Figure $9 a$ and $b$, shows sensor-level apparent reflectance and atmospherically corrected surface reflectance true colour images respectively. It is clearly evident that after atmospheric correction, the haze due to aerosol scattering in Figure $9 a$ gets cleared in Figure $9 b$. This happens due to the use of variable AOD over the scene instead of using a single AOD value for the whole scene. Figure $9 c$ and $d$ shows sensor-level apparent reflectance and atmospherically corrected surface reflectance spectrum for different features respectively. Figure $9 c$ shows that almost half of the spectrum is contaminated by water vapour absorption with strong and broad absorption features around 0.82, $0.94,1.14 \mu \mathrm{m}$ and numerous narrow absorption features at various wavelengths in the SWIR region $(2.0-2.5 \mu \mathrm{m})$. It is clear from Figure $9 d$ that after atmospheric correction, the features due to water vapour absorption are faithfully removed. The dips in apparent reflectance due to other trace gases such as oxygen (near $0.76 \mu \mathrm{m}$ ) and carbon dioxide $(1.9-2.12 \mu \mathrm{m})$ are also corrected in the figure. From Figure $9 c$ it is clear that due to aerosol scattering, the visible-NIR spectrum is modulated, where increased reflectance values are observed due to which the shape of the spectrum is deviated from that of the feature spectrum. For example, for vegetation target, the black and red curves in Figure $9 c$ show continuous increase in reflectance as we move from red to blue wavelength due to aerosol scattering. However, after atmospheric correction it is seen that the spectrum shape of the vegetated targets (black and pink curves in Figure $9 d$ ) is faithfully recovered and is similar to the pure vegetation spectrum.

\section{Atmospheric correction over water surface}

Radiance at the sensor level can be modelled using molecular and particle scattering based on existing mathematical models and gaseous absorption in the atmosphere, provided solar and satellite-viewing geometry is known. Path radiance due to Rayleigh scattering $\left(L_{r, \lambda}\right)$ computed for single scattering approximation can be expressed as ${ }^{29}$

$$
L_{\mathrm{r}, \lambda}=\tau_{\mathrm{r}, \lambda} E_{\mathrm{s}, \lambda}^{\prime} p_{\mathrm{r}}\left(\theta_{o}, \theta, \lambda\right) / 4 \pi,
$$

where

$$
\begin{aligned}
& p_{\mathrm{r}}\left(\theta_{\mathrm{o}}, \theta, \lambda\right)=\frac{\left\{P_{\mathrm{r}}\left(\gamma^{-}, \lambda\right)+\left[r_{\theta_{\mathrm{o}}}+r_{\theta}\right] P_{\mathrm{r}}\left(\gamma^{+}, \lambda\right)\right\}}{\cos \theta}, \\
& \cos \left(\gamma^{ \pm}\right)= \pm \cos \theta_{\mathrm{o}} \cos \theta-\sin \theta_{\mathrm{o}} \sin \theta \cos \varphi
\end{aligned}
$$

where $r_{\theta}$ is the Fresnel reflectance at the air-water boundary for light incident at an angle $\theta$ and $\tau_{\mathrm{r}, \lambda}$ is the Rayleigh scattering optical depth. $P_{\mathrm{r}}\left(\gamma^{ \pm}\right)$is the Rayleigh scattering phase function, which is calculated as

$$
P_{\mathrm{r}}\left(\gamma^{ \pm}\right)=(3 / 4)\left[1+\cos ^{2}\left(\gamma^{ \pm}\right)\right] \text {. }
$$



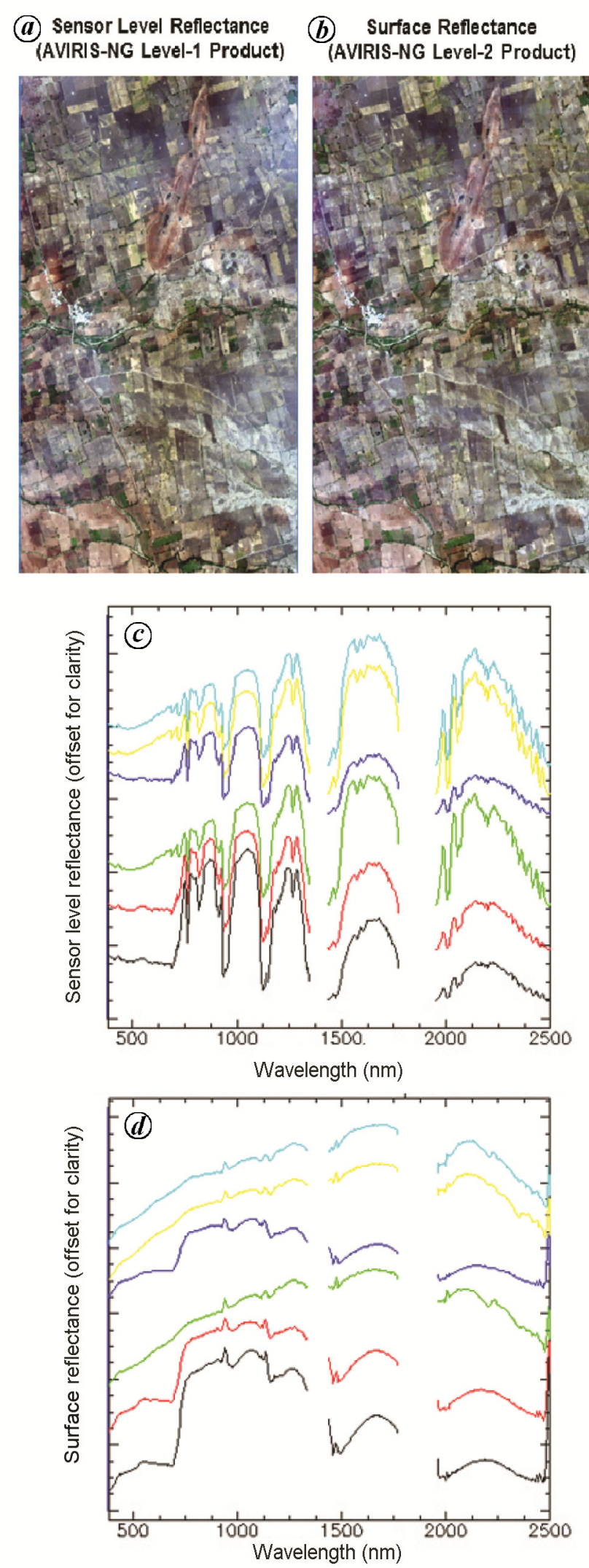

Figure 9. ( $\boldsymbol{a}, \boldsymbol{b})$ Natural colour composite of sensor-level reflectance and atmospherically corrected surface reflectance respectively. $(\boldsymbol{c}, \boldsymbol{d})$ Spectrum of sensor-level reflectance and atmospherically corrected surface reflectance respectively, for various types of targets (vegetation and bare soil pixels)
$E_{\mathrm{s}, \lambda}^{\prime}$ is the extraterrestrial solar irradiance $\left(E_{\mathrm{s}, \lambda}\right)$ corrected for its absorption at the ozone layer, and is expressed as follows

$$
E_{\mathrm{s}, \lambda}^{\prime}=E_{\mathrm{s}, \lambda} \exp \left[\tau_{\mathrm{oz}, \lambda}\left\{1 / \cos \theta_{\mathrm{o}}+1 / \cos \theta\right\}\right] .
$$

Secondly, different types of aerosols, indicating AOD $\tau_{a}$ to be wavelength-dependent can be modelled by the following power law

$$
L_{\mathrm{a}, \lambda} E_{\mathrm{s}, \lambda}^{\prime}=\beta(\lambda)^{-\alpha},
$$

where $\alpha$ is the Angstrom exponent, $L_{\mathrm{a}, \lambda}$ the path radiance due to aerosol and $\beta$ is a constant. The above equation can be solved to retrieve $\tau_{a}$ using two bands, say 1.00 and $1.55 \mu \mathrm{m}$. In this way, AOD from the data was retrieved on a pixel-to-pixel basis. Atmospheric transmittance $t$ (sun to sea surface to sensor) can be estimated using the equation

$$
t=\exp \left[-\left(\tau_{\mathrm{a}, \lambda}+\tau_{\mathrm{r}, \lambda}\right)\left\{1 / \cos \theta_{\mathrm{o}}+1 / \cos \theta\right\}\right] .
$$

Under single-scattering approximation, the radiance measured at the sensor level $\left(L_{t}\right)$ is a linear combination of atmospheric path radiance $\left(L_{\mathrm{a}}+L_{\mathrm{r}}\right)$ and water-leaving radiance $L_{\mathrm{w}}$, expressed as ${ }^{30}$

$$
L_{\mathrm{t}}=L_{\mathrm{a}}+L_{\mathrm{r}}+t_{\mathrm{u}} L_{\mathrm{w}}
$$

where $t_{\mathrm{u}}$ is defined as the diffuse transmittance of radiation from target to the top of atmosphere. Using eq. (10) to (16) in eq. (17), water-leaving radiance can be retrieved. Since the effects of water vapour absorption and

Table 4. Percentage error between retrieved Rrs and in-situ of 20 stations in Chilika lagoon, Odisha

\begin{tabular}{llc}
\hline Latitude & Longitude & Percentage error \\
\hline 19.65043 & 85.2141 & 21.9 \\
19.63206 & 85.20562 & 25.9 \\
19.61239 & 85.19638 & 16.5 \\
19.59511 & 85.18411 & 17.4 \\
19.59252 & 85.14459 & 38.4 \\
19.68882 & 85.26347 & 23.7 \\
19.67716 & 85.26204 & 22.9 \\
19.64474 & 85.19214 & 20.3 \\
19.6219 & 85.17666 & 35.2 \\
19.59511 & 85.18411 & 24.5 \\
19.5813 & 85.17477 & 14.9 \\
19.54673 & 85.15763 & 27.2 \\
19.5325 & 85.13333 & 15.6 \\
19.54726 & 85.14314 & 20.8 \\
19.71154 & 85.37883 & 22.7 \\
19.69111 & 85.21522 & 27.4 \\
19.71824 & 85.28537 & 33.9 \\
19.64544 & 85.185 & 15.4 \\
19.67371 & 85.20633 & 17.0 \\
19.69756 & 85.20774 & 28.1 \\
\hline
\end{tabular}



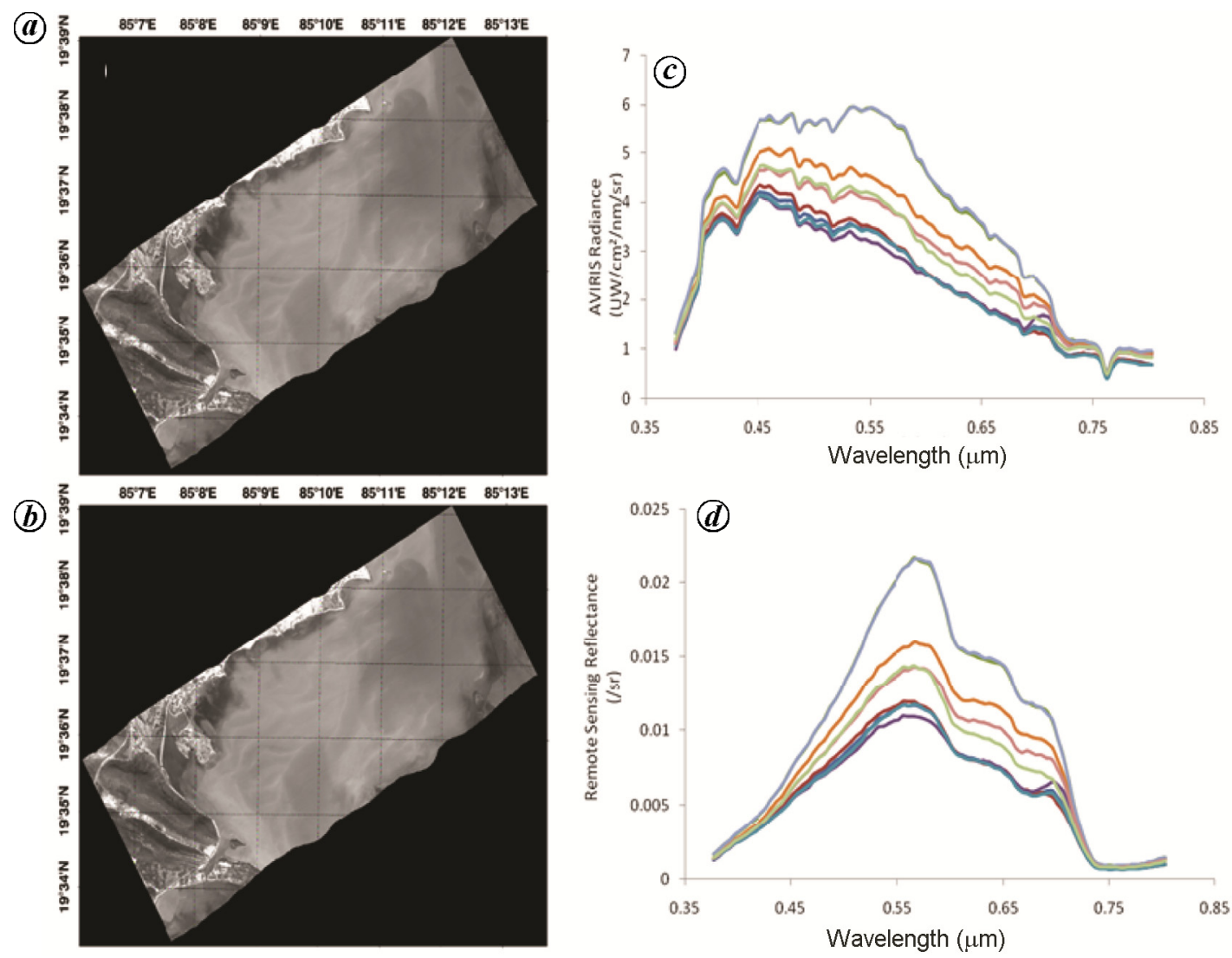

Figure 10. ( $\boldsymbol{a}, \boldsymbol{b})$ Sensor-level radiance and atmospherically corrected remote sensing reflectance respectively, over Chilika lagoon, Odisha acquired on 27 December 2015. $(\boldsymbol{c}, \boldsymbol{d})$ Spectrum of AVIRIS-NG radiance and retrieved reflectance spectra over Chilika lagoon for seven locations respectively.

gaseous absorption are negligible in the visible region of the electromagnetic spectrum, they were omitted in retrieving water-leaving reflectance.

AOD from pixel-to-pixel basis was retrieved and hyperspectral image of AVIRIS-NG was corrected for turbid and inland water bodies. Figure $10 a$ and $b$ respectively, shows the uncorrected radiance and corrected reflectance data acquired over Chilika lagoon, Odisha on 27 December 2015. Sensor-level radiance spectra and remote sensing reflectance collected at seven different locations are shown in Figure $10 c$ and $d$ respectively. Reflectance from Figure $10 d$ at seven different locations shows a peak around $0.55 \mu \mathrm{m}$. The peak indicates that the water is green probably due to high phytoplankton concentration. Figure 11 shows a comparison of remotesensing reflectance retrieved from AVIRIS-NG data and in-situ data. Error estimation was done based on Carder's approach as follows

$$
\begin{aligned}
& \text { RMSE }=\left[\left(\sum_{n=1}^{n}(\log O-\log E)^{2} / n\right]^{1 / 2},\right. \\
& \text { Error }=0.5\left[\left(10^{\mathrm{RMSE}}-1\right)+\left(1-10^{\mathrm{RMSE}}\right)\right] .
\end{aligned}
$$

Table 4 shows the percentage error estimate using eq. (19).

\section{Conclusion}

In the present study, data-processing algorithms for retrieving critical atmospheric parameters, AOD and water vapour over land and ocean surfaces using hyperspectral data acquired by AVIRIS-NG flight over the Indian region are described. Further, atmospheric correction algorithm to generate surface reflectance, i.e. AVIRISNG level-2 product over land and turbid water surfaces is also described.

AVIRIS-NG-derived AOD shows good correlation with in situ sun-photometer measurements. Water vapour derived from AVRIS-NG data shows good agreement with in situ precipitable water vapour measurements at various locations. The AVIRIS-NG-derived surface reflectance spectrum over land surface shows significant compensation in spectral regions with strong gaseous absorption such water vapour near 820, 940 and $1140 \mathrm{~nm}$, and oxygen-A near $760 \mathrm{~nm}$. Moreover, in the visible to near-infrared spectral range significant improvement due to aerosol correction is seen. Also decrease in haziness of 

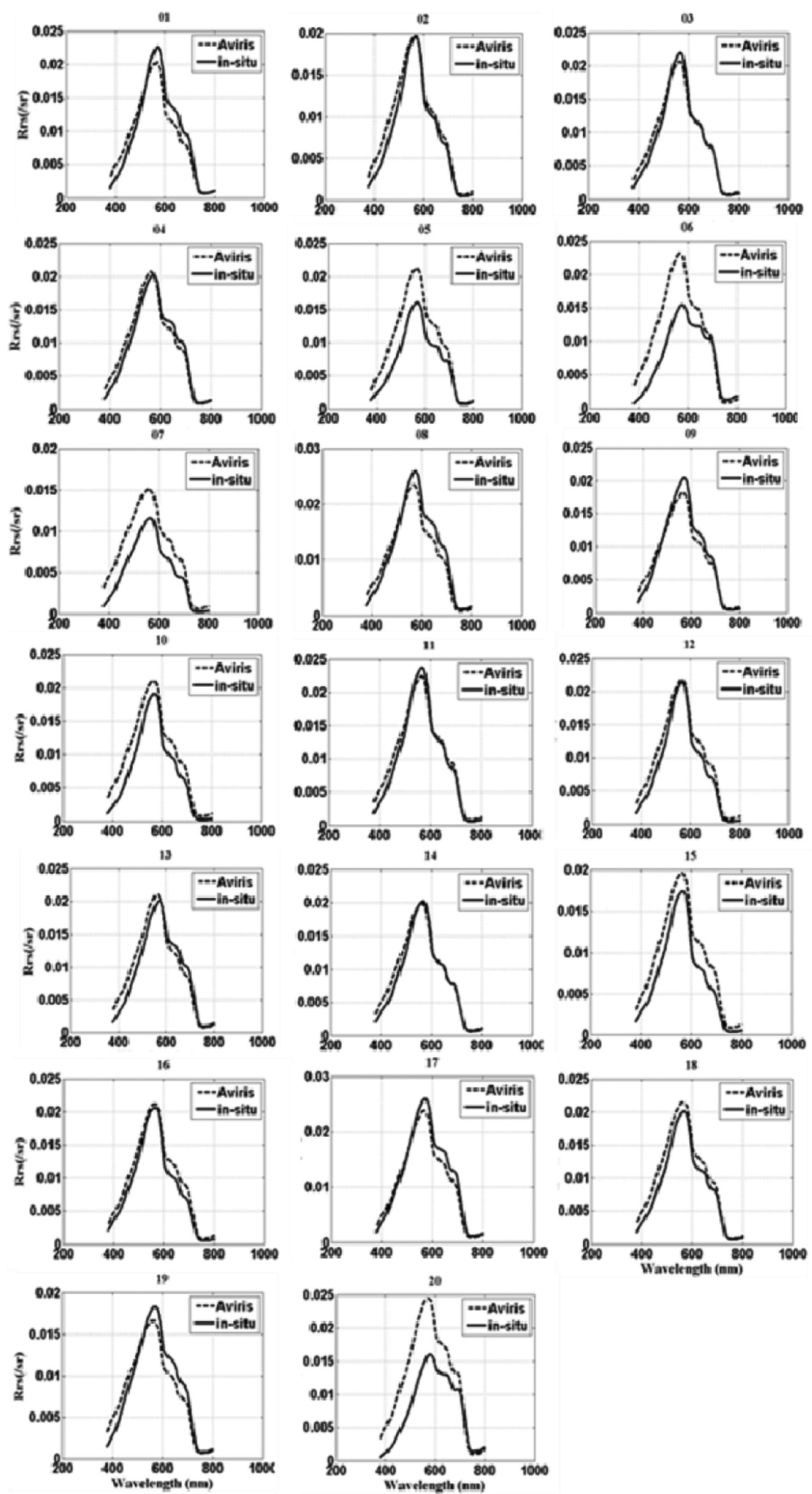

Figure 11. Comparison of AVIRIS-NG reflectance spectra with in-situ spectra at 20 different locations (dotted curve - AVIRIS-NG and solid curve - in-situ spectra). 
sensor-level image is observed after atmospheric correction. Over water surface, comparison of atmospherically corrected reflectance data of AVIRIS-NG with in-situ data of 20 stations shows fairly good match. Maximum error of $38.4 \%$ and minimum error of $14.9 \%$ are found.

1. Vane, G., Green, R. O., Chrien, T. G., Enmark, H. T., Hansen, E. G. and Porter, W. M., The Airborne Visible/Infrared Imaging Spectrometer (AVIRIS). Remote Sensing Environ., 1993, 44(2-3), 127-143; doi:10.1016/ S0034-4257 (93)90012-M.

2. Green, R. O. et al., Imaging spectroscopy and the Airborne Visible/Infrared Imaging Spectrometer (AVIRIS). Remote Sensing Environ., 1998, 65(3), 227-248; doi:10.1016/S0034-4257 (98)0064-9.

3. Hamlin, L., Green, R. O., Mouroulis, P., Eastwood, M., Wilson, D., Dudik, M. and Paine, C., Imaging spectrometer science measurements for terrestrial ecology: AVIRIS and new developments. In IEEE Aerospace Conference Proceeding, 2011, pp. 1-7; http://dx.doi.org/10.1109/AERO.2011.5747395.

4. Gao, B. C. and Goetz, A. F., Column atmospheric water vapor and vegetation liquid water retrievals from airborne imaging spectrometer data. J. Geophys. Res. - Atmos., 1990, 95(D4), 3549-3564.

5. Adler-Golden, S. M. et al., Atmospheric correction for short-wave spectral imagery based on MODTRAN4. SPIE Proc. Imag. Spectrom., 1999, 3753, 61-69.

6. Etheridge, D. M., Steele, L. P., Langenfelds, R. L., Francey, R. J., Barnola, J.-M. and Morgan, V. I., Natural and anthropogenic hanges in atmospheric $\mathrm{CO}_{2}$ over the last 1000 years from air in Antarctic ice and firn. J. Geophys. Res., 1996, 101, 4115-4128.

7. Leung, D. Y. C., Caramanna, G. and Maroto-Valer, M. M., An overview of current status of carbon dioxide capture and storage technologies. Renew. Sust. Energ. Rev., 2014, 39, 426-443.

8. Wunch, D. et al., Comparisons of the Orbiting Carbon Observatory-2 (OCO-2) $\mathrm{XCO}_{2}$ measurements with TCCON. Atmos. Meas. Tech., 2017, 10, 2209-2238.

9. Bovensmann, H., Burrows, J. P., Buchwitz, M., Frerick, J., Noel, S. and Rozanov, V. V., SCIAMACHY: mission objectives and measurement modes. J. Atmos. Sci., 1999, 5, 127-150.

10. Hamazaki, T., Kaneko, Y. and Kuze, A., Carbon dioxide monitoring from the GOSAT satellite. In Proceedings of XX ISPRS Conference, Istanbul, Turkey, 12-13 July 2004, pp. 3-5.

11. Frankenberg, C. et al., The Orbiting Carbon Observatory (OCO2): spectrometer performance evaluation using pre-launch direct sun measurements. Atmos. Meas. Tech., 2015, 8, 301-313.

12. Tadic, J. M. et al., A comparison of in situ aircraft measurements of carbon dioxide and methane to GOSAT data measured over railroad Valley Playa, Nevada, USA. IEEE Trans. Geosci. Remote Sensing, 2014, 52, 7764-7774.

13. Green, R. O., Measuring the spectral expression of carbon dioxide in the solar reflected spectrum with AVIRIS. In Proceedings of the 11th Annual Airborne Earth Science Workshop, Jet Propulsion Laboratory, Pasadena, CA, USA, 2001.

14. Dennison, P. E. et al., High spatial resolution mapping of elevated atmospheric carbon dioxide using airborne imaging spectroscopy: radiative transfer modeling and power plant plume detection. Remote Sensing Environ., 2013, 139, 116-129.

15. Thorpe, A. K. et al., Airborne DOAS retrievals of methane, carbon dioxide, and water vapor concentrations at high spatial resolution: application to AVIRIS-NG. Atmos. Meas. Tech., 2017, 10, 3833-3850.

16. Kotchenova, S. Y., Vermote, E. F., Matarrese, R. and Klemm Jr, F. J., Validation of a vector version of the $6 \mathrm{~S}$ radiative transfer code for atmospheric correction of satellite data. Part I: Path radiance. Appl. Opt., 2006, 45(26), 6762.

17. Lenoble, J., Radiative Transfer in Scattering and Absorbing Atmospheres: Standard Computational Procedures, A. Deepak Publishing, Hampton, VA.

18. Tanre, D. et al., Simulation of the Satellite Signal in the Solar Spectrum (5S), User's Guide, Laboratoire d'Optique Atmospherique, U.S.T. de Lille, 59655 Villeneuve dáscq, France, 1986.

19. Vermote, E. F., Tanre, D., Deuze, J. L., Herman, M. and Morcrette, J. J., Second simulation of the satellite signal in the solar spectrum, 6S: an overview. IEEE Trans. Geosci. Remote Sensing, 1997, 35(3), 675.

20. Kaufman, Y. J., Tanre, D. and Boucher, O., A satellite view of aerosols in the climate system. Nature, 2002, 419, 215-223.

21. Kaufman, Y. J. et al., Relationship between surface reflectance in the visible and mid-IR used in MODIS aerosol algorithm - theory. Geophys. Res. Lett., 2002, 29(23), 31-1-31-4.

22. Kaufman, Y. J. et al., The MODIS $2.1 \mu \mathrm{m}$ channel-correlation with visible reflectance for use in remote sensing of aerosol. IEEE Transactions on Geoscience and Remote Sensing, 1997, 35(5), 1286-1298.

23. Hsu, N. C. et al., Enhanced deep-blue aerosol retrieval algorithm: the second generation. J. Geophys. Res.: Atmos., 2013, 118, 92969315; https://doi.org/10.1002/jgrd.50712.

24. Mishra, M. K., Retrieval of aerosol optical depth from INSAT-3D imager over Asian landmass and adjoining ocean: retrieval uncertainty and validation. J. Geophys. Res.: Atmosp., 2018, 123; https://doi.org/10.1029/2017JD028116.

25. Bruegge, C. J. et al., In situ atmospheric water-vapor retrieval in support of AVIRIS validation. Proc. SPIE, 1990, 1298, 150163.

26. Fowle F. E., The spectroscopic determination of aqueous vapour. Astrophys. J., 1912, 35, 149-162.

27. Frouin, R., Deschamps, Pierre-Yves and Lecomte, P., Determination from space of atmospheric total water vapor amounts by differential absorption near $940 \mathrm{~nm}$ : theory and airborne verification. J. Appl. Meteorol., 1990, 29, 448-460.

28. Berk, A., Bernstein, L. S. and Robertson, D. C., MODTRAN: a moderate resolution model for LOWTRAN7. GL-TR-89-0122. Air Force Geophysical Laboratory, Hanscom AFB, MA, 1989, p. 38.

29. Gordon, H. R., Brown, J. W. and Evans, R. H., Exact Rayleigh scattering calculations for use with the Nimbus 7 coastal zone color scanner. Appl. Opt., 1988, 27, 862-871.

30. Gordon, H. R., Atmospheric correction of ocean color imagery in the Earth Observing System era. J. Geophys. Res., 1997, 102, 17081-17106.

doi: $10.18520 / \mathrm{cs} / \mathrm{v} 116 / \mathrm{i} 7 / 1089-1100$ 